\title{
NITROGÊNIO E MATÉRIA ORGÂNICA EM DOIS RIOS COM DIFERENTES GRAUS DE IMPACTOS NO SISTEMA ESTUARINO DE SANTOS (SÃO PAULO, BRASIL).
}

\author{
SUTTI, B.O.*; BORGES, R.P.; GUIMARÃES, L.L. \& SCHMIEGELOW, J.M.M. \\ PPG em Sustentabilidade de Ecossistemas Costeiros e Marinhos, Universidade Santa Cecília, SP, \\ Brasil \\ *Corresponding author: suttioceano@yahoo.com.br
}

\begin{abstract}
Sutti, B.O.; Borges, R.P.; Guimarães, L.L. \& Schmiegelow, J.M.M., (2016). Nitrogênio e matéria orgânica em dois rios com diferentes graus de impactos no sistema estuarino de Santos (São Paulo, Brasil). Braz. J. Aquat. Sci. Technol. 20(1). elSSN 1983-9057. DOI: 10.14210/bjast.v20n1. Two sampling campaigns were carried out in October 2012 and other two in January 2013 to evaluate seasonally and spatially the main forms of dissolved inorganic nitrogen (DIN) and particulate organic matter (POM) in surface waters of the two largest rivers of Santo Amaro Island (São Paulo, Brazil), Maratuã and Crumaú. These rivers have similar physical characteristics, but different levels of anthropogenic interference. One fixed oceanographic station was defined at downstream of each river, and a third upstream of Crumaú River. This last site exhibits low values of dissolved oxygen (DO) with high ammonia-N concentrations in relation to the MOP and to other forms of NID. These facts point that the leachate landfill is the most significant contribution of nitrogen to these waters than the gross sewage dumps (stilt community), both located near the Crumaú River nascent. The sharp decline of DIN in downstream of the Crumaú River indicates that the volatilization/denitrification is the main nitrogen removal process. On the other hand, the good state of the mangrove in downstream of Maratuã River explains the higher OM concentrations in this place, where the nitrification was more significant due to higher levels of DO and nitrate. This nutrient had an increase of $50 \%$ in the rainy season, with peak concentrations downstream of the rivers. The high current velocities of these rivers are an alert to occurrences of eutrophication in the estuary upstream, which is considerably shallower and with lower circulation than Crumaú and Maratuã rivers.
\end{abstract}

Keywords: Estuaries, Mangroves, Nitrogen, Eutrophication, Anthropogenic interference, Water quality.

\section{INTRODUÇÃO}

O processo de fixação disponibiliza o nitrogênio à vida com base na ação de um pequeno grupo de bactérias capazes de romper a tripla ligação do $\mathrm{N}_{2}$ (nitrogênio molecular), e assim permitir a existência de formas reativas orgânicas e inorgânicas (Troeh \& Thompson, 2007). Em condições aeróbicas o processo de nitrificação oxida o amônio $\left(\mathrm{NH}_{4}^{+}\right)$a nitrito $\left(\mathrm{NO}_{2}^{-}\right)$e nitrato $\left(\mathrm{NO}_{3}^{-}\right)$(Baird, 2002). Já em condições anaeróbicas, a desnitrificação reduz o nitrato a nitrito e amônio, ou o transforma em óxido nitroso $\left(\mathrm{N}_{2} \mathrm{O}\right)$, ou ainda a $\mathrm{N}_{2}$ (Lenzi et al., 2012), equilibrando o sistema. Entretanto, o aumento de formas reativas antropogênicas pode ser uma influência significativa às mudanças climáticas quando ocorridas como $\mathrm{N}_{2} \mathrm{O}$, uma vez que esta molécula é cerca de 300 vezes mais "eficiente" na retenção de calor do que o dióxido de carbono $\left(\mathrm{CO}_{2}\right)$ (Galloway et al., 2008).

$O$ nitrogênio atinge águas costeiras principalmente via deposição atmosférica, efluentes de esgotos, descargas fluviais e fluxo de águas subterrâneas (Kroeger et al., 2006). No ambiente marinho, os organismos autótrofos assimilam predominantemente as formas inorgânicas dissolvidas (nutrientes), como os íons amônio, nitrito e nitrato (Braga, 2002).
Em estuários tropicais e subtropicais, manguezais contribuem sobremaneira para o aumento da matéria orgânica no sistema, sendo também importante na ciclagem desses nutrientes, que ocorre tipicamente junto ao substrato (Rezende et al., 2007), onde a comunidade bacteriana é determinante na biodisponibilidade desses íons (Fernandes et al., 2012). Estes frequentemente migram à coluna d'água em função das correntes de marés, expressivamente em regiões de macromaré (Dittmar \& Lara, 2001), e/ou em zonas estuarinas de baixa profundidade (Ovalle et al., 1990).

Os despejos de esgotos e as atividades agrícolas frequentemente causam a eutrofização desses ambientes pelo aumento do nitrogênio reativo (Mallin et al., 1993; Savage, 2005). O desequilíbrio ecológico ocasionado por estas ações é a principal causa de zonas costeiras mortas, bem como da consequente perda de biodiversidade (Rabelais et al., 2002). Nesse sentido, a quantificação da matéria orgânica e das principais formas de nitrogênio nesses ecossistemas podem revelar desequilíbrios decorrentes de catástrofes naturais e/ou antropogênicas.

$\mathrm{O}$-amoniacal $\left(\mathrm{NH}_{3}+\mathrm{NH}_{4}^{+}\right)$, gerado em grande escala pela decomposição das substâncias contidas em esgotos sanitários, consome acentuadamente o oxigênio dissolvido (Savage, 2005), além de ser um 
tóxico bastante restritivo à vida dos peixes em concentrações acima de $5 \mathrm{mg} . \mathrm{L}^{-1}$ (Pereira, 2004). O nitrato é a forma nitrogenada mais utilizada na agricultura (Troeh \& Thompson, 2007), e seu aumento na água potável pode causar metaemoglobineína infantil, uma doença normalmente letal (Piveli \& Kato, 2006).

No sistema estuarino de Santos, a eutrofização das águas dos canais de São Vicente e Porto de Santos é habitualmente avaliada pela Companhia Ambiental do Estado de São Paulo (CETESB) e pela comunidade científica. Nesses canais, os ciclos biogeoquímicos dos nutrientes são altamente influenciados pelo complexo industrial, esgotos sanitários e atividades portuárias (Braga et al., 2000; Berbel et al., 2015). Já a influência antropogênica na qualidade das águas do canal de Bertioga pouco foi estudada, com destaque apenas para Gianesella et al. (2005), que avaliou a dinâmica de nutrientes em curta escala de tempo.

As características das águas da posição mediana do canal de Bertioga são ainda menos estudadas por ser uma área relativamente mais distante dos centros urbanos, e também por ser um local de difícil navegação devido às baixas profundidades. Essa região do canal de Bertioga recebe a maior drenagem da Ilha de Santo Amaro (Guarujá-SP), principalmente dos rios Maratuã e Crumaú, que apresentam distintos níveis de intervenções antropogênicas. Com base nisso, o objetivo deste estudo foi avaliar sazonalmente e espacialmente a matéria orgânica e as principais formas de nitrogênio inorgânico dissolvido nas águas superficiais desses rios.

\section{MATERIAIS E MÉTODOS}

\section{Área de Estudo}

Os rios Maratuã e Crumaú estão localizados no centro-norte da Ilha de Santo Amaro (litoral central de São Paulo), desaguando no Largo do Candinho, uma área estuarina de até $1 \mathrm{~km}$ de largura na porção mediana do Canal de Bertioga (Figura 1), onde, segundo Harari \& Camargo (1998), é um local de baixa hidrodinâmica devido a divergência das vazantes (ou convergência das enchentes) durante o ciclo da maré. De acordo com Schmiegelow \& Gianesella (2014), essa região é ocupada por manguezais constituídos por três espécies arbóreas: Rhizophora mangle, Laguncularia racemosa e Avicennia schaueriana.

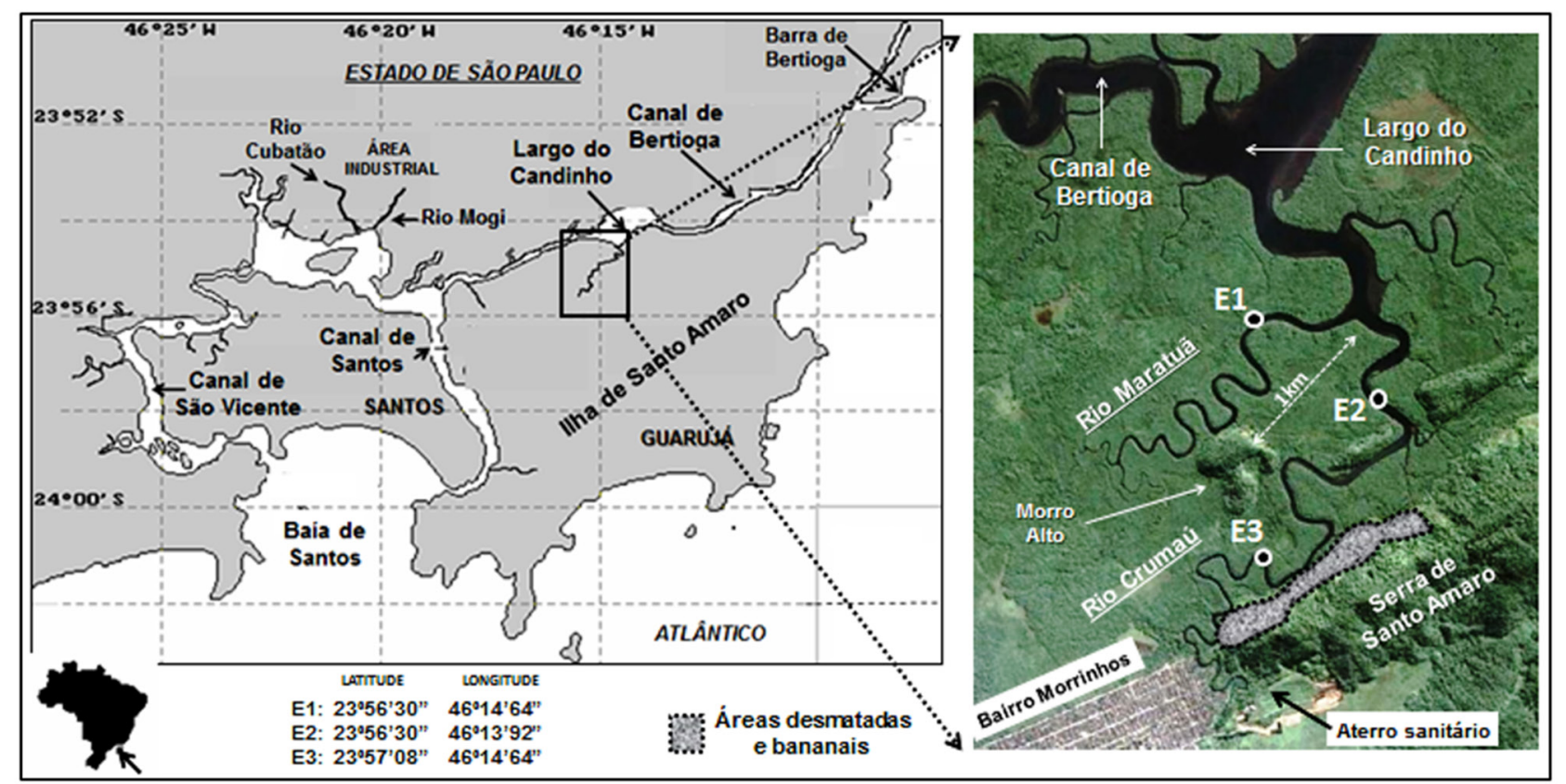

Figura 1 - À direita, sistema estuarino de Santos (adaptado de Gianesella et al., 2005). À esquerda, área de estudo apresentando as estações oceanográficas (E1, E2 e E3), bem como a pressão antropogênica na região estuarina centro-norte da llha de Santo Amaro.

Os dois rios apresentam características físicas similares, meandrando paralelamente até se unirem em um curto canal que faz conexão ao Largo do Candinho. As profundidades variam de $1 \mathrm{a} 7 \mathrm{~m}$, com uma média no canal principal em torno de $2,5 \mathrm{~m}$. O Rio Maratuã encontra-se relativamente mais próximo ao Canal de Bertioga e as vegetações de suas margens apresentam-se em bom estado de preservação. Já o Rio Crumaú recebe a drenagem de parte de uma das vertentes da Serra de Santo Amaro, onde parte da vegetação original deu lugar a áreas agrícolas, constituídas principalmente por bananais (Figura 2). Nos arredores da nascente deste rio (Bairro Morrinhos), famílias vivem em palafitas próximas ao aterro sani- 
tário do saco do funil (atualmente desativado) (Figura 1).

O clima na Baixada Santista é classificado como Tropical Úmido e o regime de chuvas é controlado tanto por sistemas intertropicais como extratropicais (Nunes, 1997). A temperatura atmosférica apresenta pouca variabilidade anual, enquanto que os índices pluviométricos são mais intensos no verão (Figura 3) (CIIAGRO, 2013). A maré, a descarga de água doce, o gradiente de densidade, o vento e a circulação costeira são as principais forças geradoras da circulação e dos processos de misturas das águas do sistema estuarino de Santos (Miranda et al., 2002).

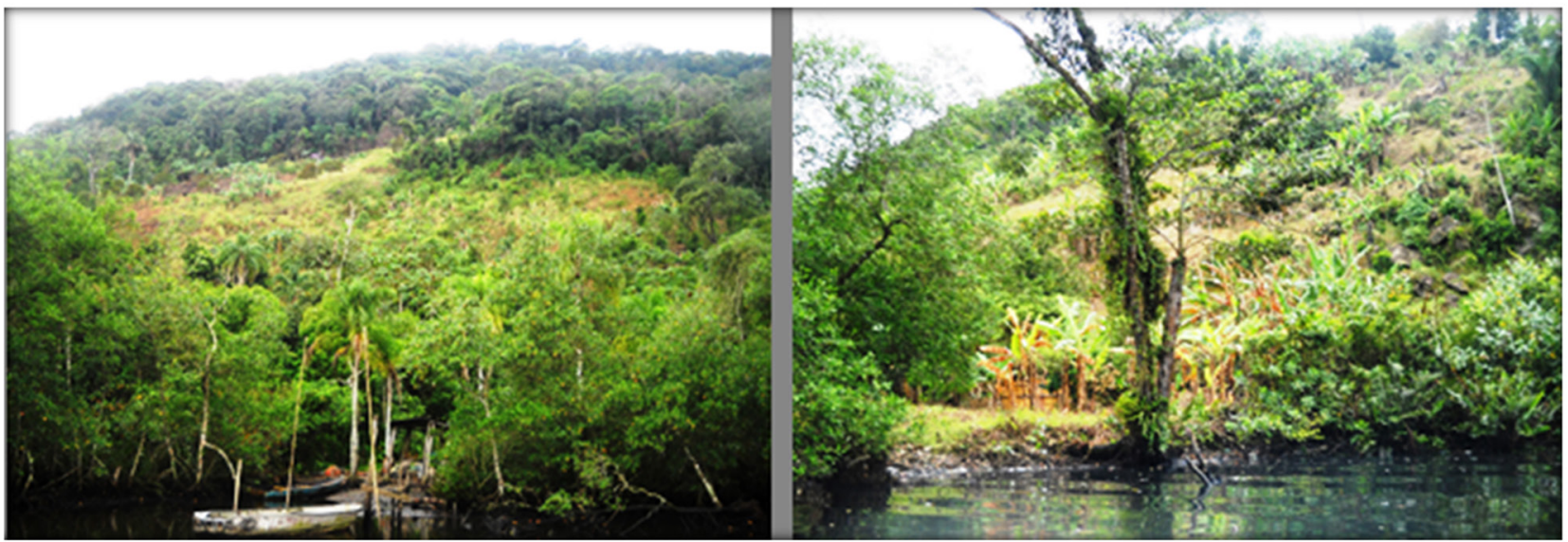

Figura 2 - Áreas desmatadas utilizadas para o cultivo de bananas nas encostas da Serra de Santo Amaro ao longo da margem leste do Rio Crumaú.

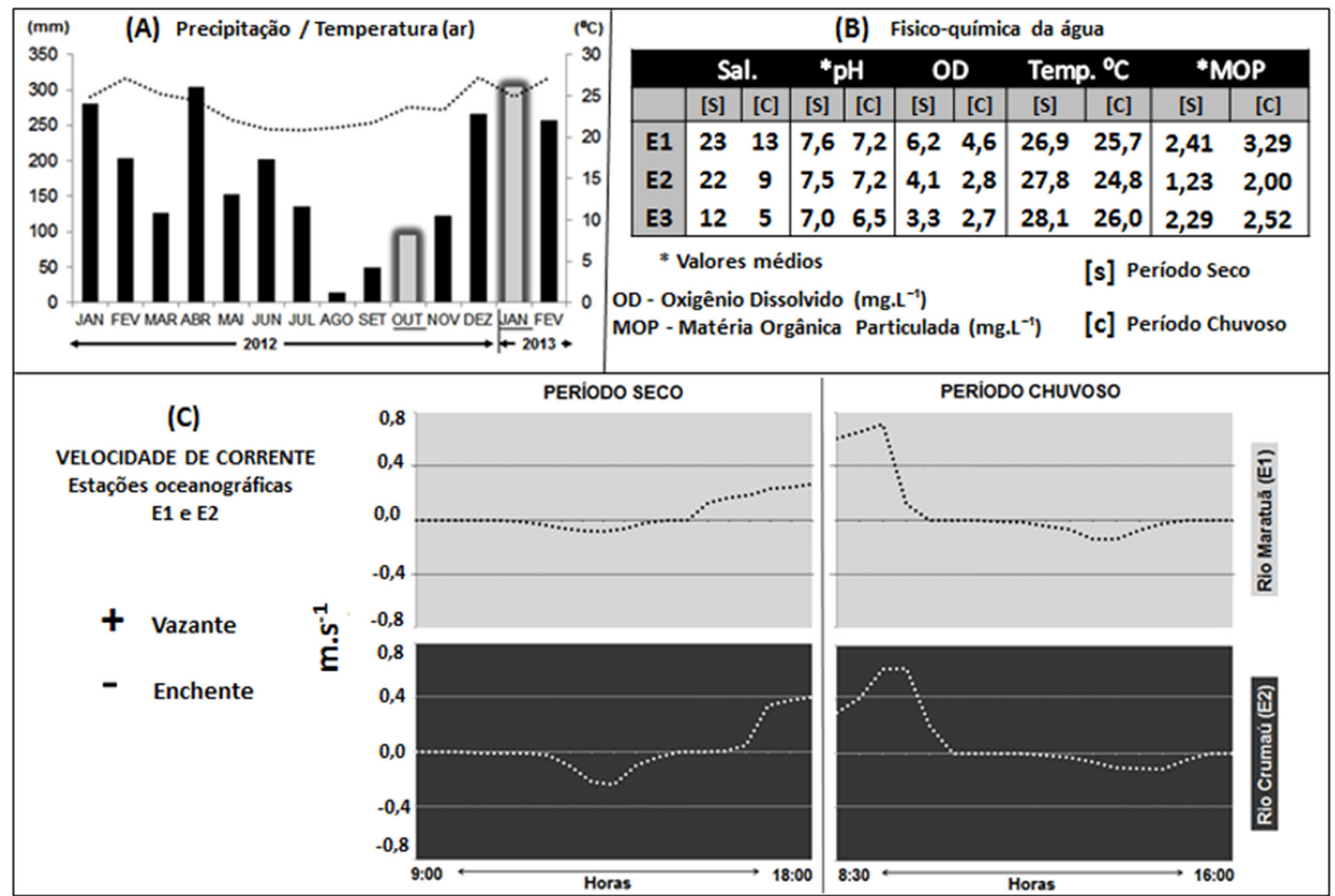

Figura 3 - Figura (A): preciptação média (em cor cinza, os meses de amostragem) (CIIAGRO, 2013). Figura (B): parâmetros fisico-quimicos das águas superficiais das estaçoes oceanográficas (E1, E2 e E3). Figura (C): velocidades de correntes monitoradas em intervalos de 30 minutos nas águas superficiais das estaçoes E1 e E2. 


\section{Estratégia amostral}

Foram definidas três estações oceanográficas (E1, E2 e E3), sendo E1 e E2, localizadas, respectivamente, nas jusantes dos rios Maratuã e Crumaú, e E3 na região a montante deste último, próximo à comunidade de palafitas e ao aterro sanitário do Bairro Morrinhos (Figura 1). As campanhas de amostragem foram realizadas em dias consecutivos: 28-29 de outubro de 2012 (período seco) e 27-28 de janeiro de 2013 (período chuvoso). Dados de pluviometria foram obtidos da estação pluviométrica de SantosSP (CIIAGRO, 2013). Através de sonar e GPS M52 (Lowrance ${ }^{\circledR}$ ) foram registradas as coordenadas geográficas das estações oceanográficas, bem como a profundidade na maior parte da extensão dos rios.

Nas estações oceanográficas E1 e E2, as velocidades de corrente foram medidas por fluxômetro mecânico (General Oceanics $₫$ 2030R6) em intervalos de $30 \mathrm{~min}$, cobrindo a maior parte dos ciclos das marés (sizígias), sendo as coletas de água realizadas em momentos de elevada hidrodinâmica nas vazantes. $\mathrm{Na}$ estação $\mathrm{E} 3$, as coletas foram realizadas nas estofas das marés (baixamar no período seco e preamar no chuvoso), não havendo medição de corrente. As amostras foram coletadas em triplicata com garrafa van Dorn, transferidas em frascos de polipropileno (1L) de cor âmbar, que foram armazenados com gelo até as análises em laboratório.

\section{Procedimentos analíticos}

Oxigênio dissolvido (OD) e salinidade foram determinados em campo durante as coletas de água, respectivamente pelo oxímetro MO-910 e pelo refratômetro RTS-101ATC, ambos da marca Instrutherm®. O percentual de saturação em oxigênio dissolvido (\% Sat. OD) foi obtido pelas equações em Grassholf et al. (1983).

Através de método gravimétrico, os sólidos suspensos foram obtidos pela porção do resíduo total retida na membrana (GF/3F - Axiva®) de fibra de vidro de porosidade de $1,2 \mu \mathrm{m}$, sendo a fração orgânica particulada (sólidos voláteis) determinada através de calcinação em forno de mufla à $550^{\circ} \mathrm{C}$ por uma hora, conforme a norma NBR 10664 (1989).

$\mathrm{O} \mathrm{pH}$ das amostras foi medido pelo pHmetro (micronal ${ }^{\circledR}$, modelo B474). O nitrogênio amoniacal (N-amoniacal) foi determinado pela metodologia volumétrica 4500-D com destilação preliminar (APHA, 1999). Já nitratos $\left(\mathrm{N}-\mathrm{NO}_{3}^{-}\right)$e nitritos $\left(\mathrm{N}-\mathrm{NO}_{2}{ }^{-}\right)$ foram determinados por método colorimétrico com leitura em espectrofotômetro (APHA, 2005), a partir de volumes $(100 \mathrm{~mL})$ filtrados em bomba de vácuo, utilizando-se membranas de acetato de celulose (AP40 - Millipore () com porosidade de 0,45 um, conforme Prista (2012). Os valores de Nitrogênio Inorgânico
Dissolvido (NID) foram estabelecidos pela soma de $\mathrm{N}$-amoniacal $(\mathrm{N}-\mathrm{N})$, nitrato $\left(\mathrm{N}-\mathrm{NO}_{3}{ }^{-}\right)$e nitrito $\left(\mathrm{N}-\mathrm{NO}_{2}{ }^{-}\right)$.

\section{Procedimentos Estatísticos}

Os resultados das análises foram expressos como média \pm desvio padrão para cada local analisado, através do software GraphPad Prism $®$ for Windows versão 5.03. A matriz de correlação incluiu os valores dos parâmetros determinados em laboratório e os valores dos parâmetros obtidos em campo. A análise de correlação de Pearson foi realizada pelo software Statistica 7.0® com grau de significância em $p \leq 0,05$.

\section{RESULTADOS}

\section{Hidrologia e propriedades físico-químicas}

O total pluviométrico registrado no mês de outubro de 2012 foi de $95,5 \mathrm{~mm}$, enquanto que no mês de janeiro de 2013 foi de 303,8mm (Figura 3), sendo que nos cinco dias anteriores as campanhas de amostragem deste último período houve um acúmulo de 44,7mm (CIIAGRO, 2013). Os períodos apresentaram pouca influência de ventos, com velocidades que variaram de 6 a $18 \mathrm{~m} . \mathrm{s}^{-1}$ nas direções L e SE (CPTEC, 2013).

O período chuvoso apresentou correntes de vazantes consideravelmente superiores as de enchentes, ao contrário do ocorrido no período seco, quando as de vazantes estiveram pouco mais intensas que às de enchentes. As velocidades das correntes de enchente variaram de 0,08 (seco) a $0,14 \mathrm{~m} . \mathrm{s}^{-1}$ (chuvoso) na estação E1 e de 0,11 (seco) a 0,24 m.s. (chuvoso) na estação E2, enquanto que as de vazante variaram de 0,27 (seco) a $0,71 \mathrm{~m} \cdot \mathrm{s}^{-1}$ (chuvoso) na estação E1 e de 40,7 (seco) a 0,68 cm.s $\mathrm{s}^{-1}$ (chuvoso) na estação E2.

No período seco, as salinidades das águas superficiais das estações E1 (jusante-Maratuã) e E2 (jusante-Crumaú) foram respectivamente 23 e 22. No período chuvoso, a estação $E 1$ apresentou salinidade 13 e a estação E2, 9. No Rio Crumaú este parâmetro variou entre 5 (E3) e 9 (E2) no período chuvoso e entre 12 (E3) e 22 (E2) no seco. A faixa de $\mathrm{pH}$ nas águas superficiais das estações foi estreita com valores máximos no período seco (Figura 3). As temperaturas da água estiveram acima de $24^{\circ} \mathrm{C}$, com valores no período seco cerca de $2^{\circ} \mathrm{C}$ superiores aos do chuvoso. Os teores de OD declinaram no período chuvoso, com valor máximo na estação $\mathrm{E} 1$ e mínimo na E3 (Figura 3). 


\section{Percentuais de saturação do oxigênio dissolvido (\% Sat. OD)}

As águas das três estações oceanográficas apresentaram percentuais de saturação de oxigênio dissolvido inferiores no período chuvoso em relação ao seco. Espacialmente, os percentuais aumentaram com a distância das palafitas e do aterro sanitário em ambos os períodos (Tabela 1).

Tabela 1 - Resultados da saturação de oxigênio dissolvido nas águas superficiais das estações oceanográficas.

\begin{tabular}{c|c|c|c|c}
\hline & Estações & OD teórico & Oxigênio in situ & \% saturação de OD \\
\hline \multirow{3}{*}{ SECA } & E1 & 7,00 & 6,20 & $89 \%$ \\
& E2 & 6,93 & 4,10 & $59 \%$ \\
& E3 & 7,25 & 3,30 & $46 \%$ \\
\hline \multirow{2}{*}{ CHUVA } & E1 & 7,35 & 4,60 & $63 \%$ \\
& E2 & 7,86 & 2,80 & $36 \%$ \\
& E3 & 7,69 & 2,10 & $35 \%$ \\
\hline
\end{tabular}

Nitrogênio inorgânico Dissolvido (NID)

Nas águas superficiais da estação $E 3$, o $\mathrm{N}$-amoniacal $(\mathrm{N}-\mathrm{N})$ atingiu concentrações superiores a 9,0 mg. $\mathrm{L}^{-1}$, representando cerca $95 \%$ do NID no período seco e cerca de $80 \%$ no chuvoso. Já na região jusante dos rios, as concentrações apresentaram-se consideravelmente reduzidas, com valores inferiores a 1,0 mg. $\mathrm{L}^{-1}$, onde esta forma de nitrogênio representou respectivamente cerca de 74 e $55 \%$ do NID no período seco, e cerca de 21 e $17 \%$ no chuvoso.

Nas águas superficiais das três estações, o nitrato foi a forma nitrogenada que mais respondeu à sazonalidade, apresentando um aumento em torno de $50 \%$ no período chuvoso. Neste período, este íon representou cerca de $84 \%$ do NID na estação E1, $79 \%$ na E2 e $20 \%$ na E3, contra aproximadamente $44 \%$ (E1), 25\% (E2) e 5\% (E3) no período seco. Com relação ao nitrito, as concentrações obtidas estiveram relativamente baixas em ambos os períodos, representando menos de $0,2 \%$ do NID nas águas superficiais das três estações, com concentração máxima de $0,013 \mathrm{mg} \cdot \mathrm{L}^{-1}$ na estação E2 no período seco (Figura 4).

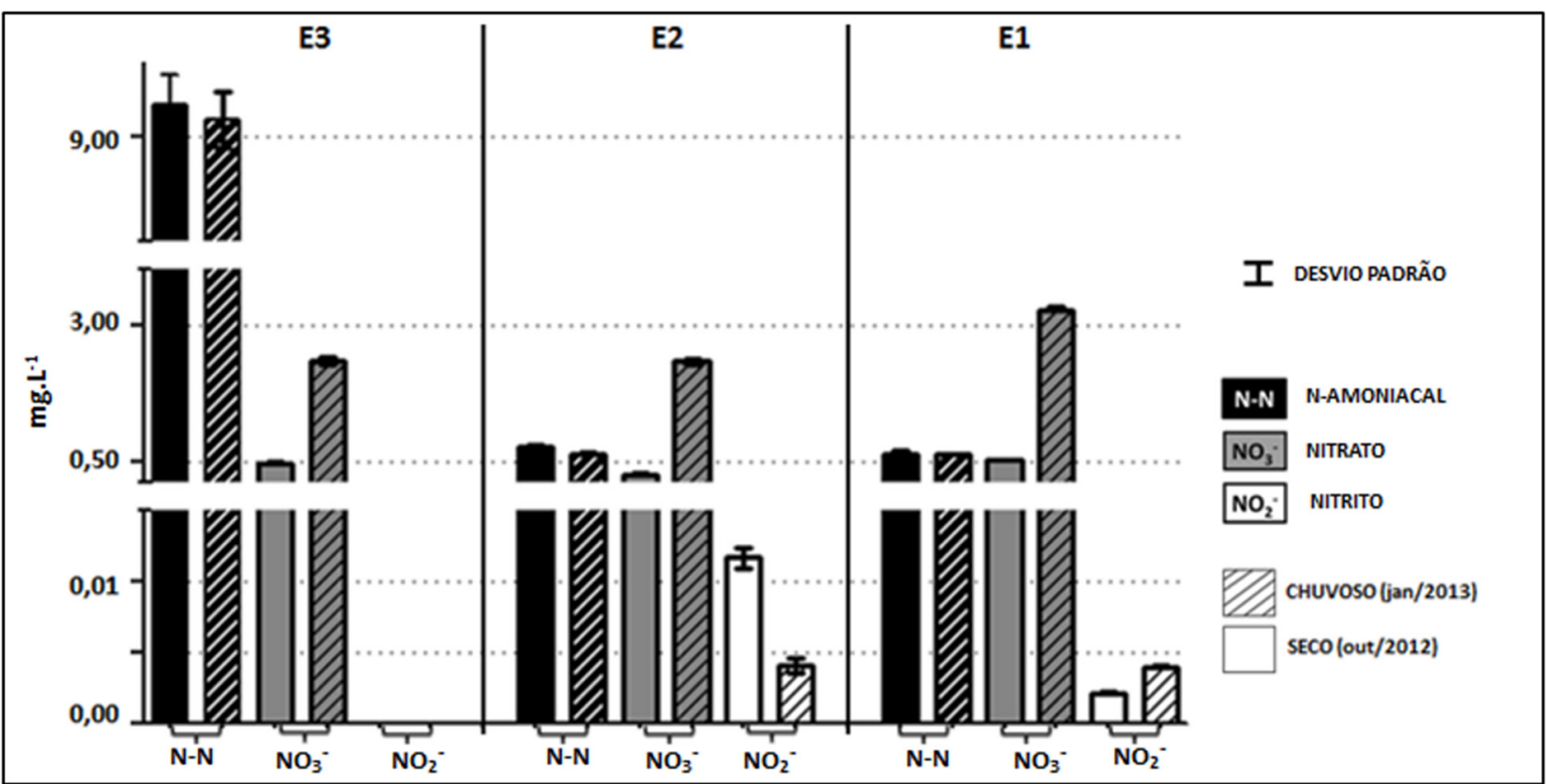

Figura 4 - Concentrações das principais formas de Nitrogênio Inorgânico Dissolvido (NID) nas águas superficiais das estações oceanográficas E3, E2 e E1.

\section{Qualidade da água em face da legislação vigente \\ As águas da região estuarina centro-norte da Ilha de Santo Amaro são enquadradas como salobras $(0,5 \leq$ salinidade $<30)$ de Classe 2 , que referem-se às águas destinada à pesca amadora e à recreação de contato secundário, conforme a Resolução 357 do CONAMA de 2005. Como a amônia é mais tóxica que o íon amônio e prevalece em faixa mais elevada de $\mathrm{pH}$, a mesma Resolução estabelece limites de $\mathrm{N}$-amoniacal na água em função do $\mathrm{pH}$ para diferentes classes, sendo as de Classe 2 em faixa 6,5-8,5 (Tabela 2).}

Tabela 2 - Valores médios ( $n=3)$. Qualidade das águas superficiais nas estações oceanográficas (E1, E2 e E3) em face aos limites da Resolução CONAMA 357/2005 para águas salobras de Classe 2. Indicados em preto estão os valores não atendidos pela Resolução. Limite máximo $\left(^{*}\right)$ e mínimo $\left(^{* *}\right)$. Limite de Detecção do Método $($ LDM $)=0,02 \mathrm{mg} \cdot \mathrm{L}^{-1}$.

\begin{tabular}{|c|c|c|c|c|c|c|c|}
\hline \multirow{2}{*}{ Parâmetros } & \multirow{2}{*}{$\begin{array}{c}\text { Limites } \\
\text { CONAMA }\end{array}$} & \multicolumn{2}{|c|}{ E3 } & \multicolumn{2}{|c|}{ E2 } & \multicolumn{2}{|c|}{ E1 } \\
\hline & & Seca & Chuva & Seca & Chuva & Seca & Chuva \\
\hline $\begin{array}{c}\mathrm{pH} \\
\mathrm{OD}\left(\mathrm{mg} \cdot \mathrm{L}^{-1}\right)\end{array}$ & 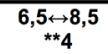 & $\begin{array}{l}7,02 \\
3,30\end{array}$ & $\begin{array}{l}6,47 \\
2,70\end{array}$ & $\begin{array}{l}7,55 \\
4,10\end{array}$ & $\begin{array}{l}7,18 \\
2,80\end{array}$ & $\begin{array}{l}7,55 \\
6,20\end{array}$ & $\begin{array}{l}7,21 \\
4,60\end{array}$ \\
\hline $\mathrm{N}$-amoniacal (mg.L- & ${ }^{\star} 0,7$ & & & & & & \\
\hline 1) & & 9,3 & 9,16 & 0,76 & 0,62 & 0,63 & 0,63 \\
\hline Nitrito (mg. $\left.\mathrm{L}^{-1}\right)$ & $* 0,2$ & $<\overline{L D M}$ & $<$ LDM & $\overline{0,012}$ & 0,004 & 0,002 & 0,004 \\
\hline Nitrato $\left(\mathrm{mg} \cdot \mathrm{L}^{-1}\right)$ & $* 0,7$ & 0,46 & 2,33 & 0,25 & 2,33 & 0,51 & 3,25 \\
\hline MOP (mg. L-1) & --. & 2,41 & 3,21 & 1,23 & 2,01 & 2,29 & 2,52 \\
\hline
\end{tabular}


No período chuvoso, as concentrações de $\mathrm{N}$-amoniacal no Rio Crumaú (estações E3 e E2) estiveram acima do limite imposto pela legislação. Nas águas da estação $\mathrm{E} 3$, as concentrações desta forma de nitrogênio superaram em dez vezes o máximo estipulado pela Resolução em ambos os períodos. Os valores de nitrato observados no período chuvoso superaram o limite nas três estações, ao contrário do ocorrido no período seco, quando as concentrações estiveram abaixo do limite. Já as concentrações de nitrito estiveram consideravelmente abaixo do limite nas três estações em ambos os períodos. As três formas nitrogenadas apresentaram limites de detecção do método em torno de $0,02 \mathrm{mg} \cdot \mathrm{L}^{-1}(0,1 \mu \mathrm{M})$, similares aos encontrados por Braga et al. (2000), Azevedo \& Braga (2011) e Chiozzini et al. (2011).
Matéria Orgânica Particulada (MOP) e Nitrogênio Inorgânico Dissolvido (NID)

O Nitrogênio Inorgânico Dissolvido (NID) diminuiu consideravelmente nas águas superficiais do Rio Crumaú no sentido montante-jusante em ambos os períodos (Figura 5). No período seco os valores na estação E3 (9,8 mg.L $\left.\mathrm{L}^{-1}\right)$ estiveram aproximadamente dez vezes superiores aos verificados na estação E2 (1,0 mg. $\left.\mathrm{L}^{-1}\right)$, enquanto que no período chuvoso essa diferença diminuiu, com concentrações na estação E3 $\left(11,5 \mathrm{mg} \cdot \mathrm{L}^{-1}\right)$ cerca de quatro vezes superiores às da estação E2 (2,9 mg. $\left.\mathrm{L}^{-1}\right)$. Já nas águas superficiais da estação $E 1$ os valores estiveram pouco superiores aos da estação E2 em ambos os períodos (Figura 5).

As concentrações de MOP variaram menos que às de NID, tanto sazonalmente como espacialmente,

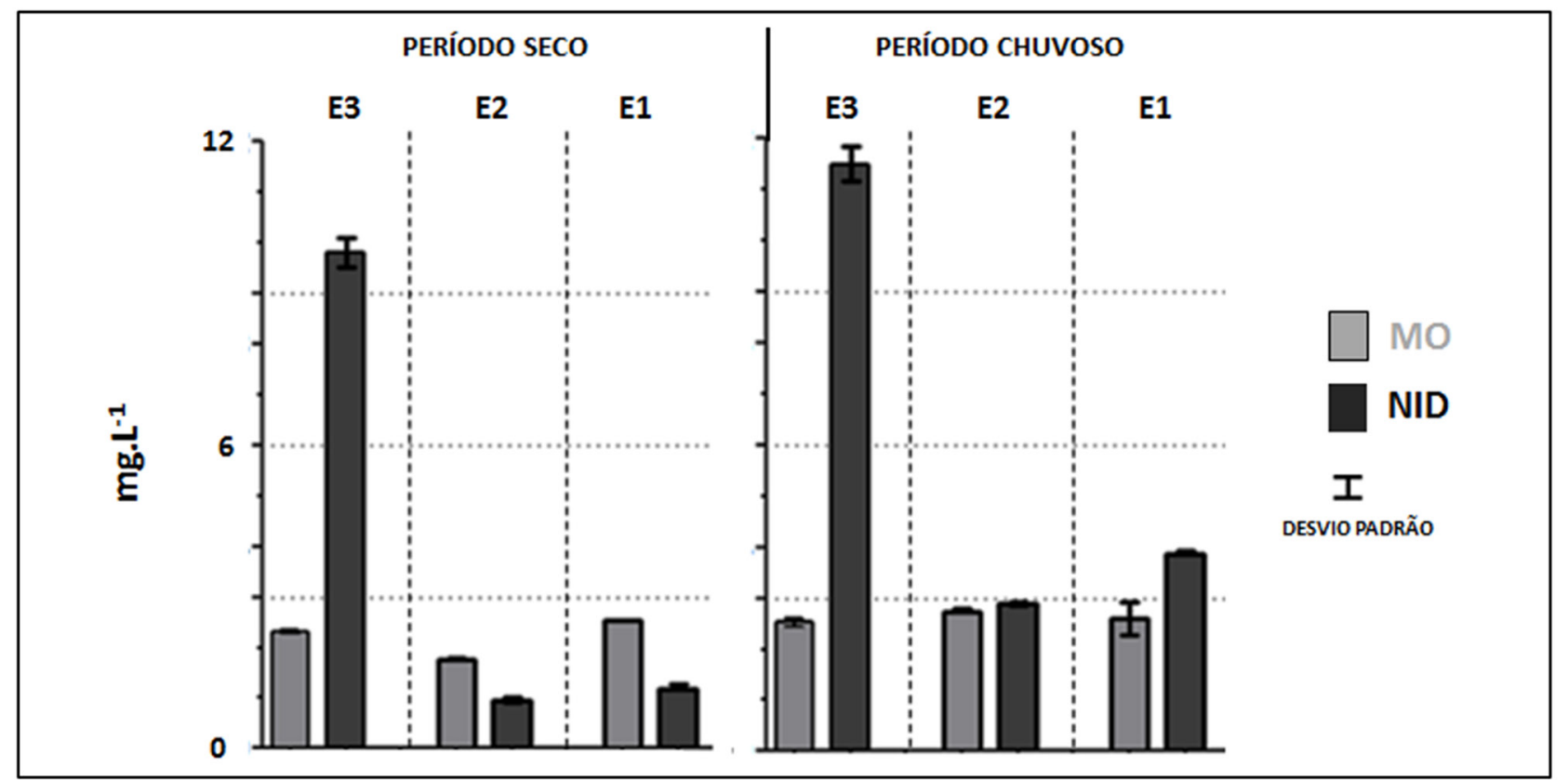

Figura 5 - Concentrações de MOP (cinza) e NID (preto) nas águas superficiais das estações E3, E2 e E1.

com valores mínimos na estação E2 no período seco e máximos na estação $\mathrm{E} 1$. Os teores de MOP foram superiores aos de NID somente no período seco nas águas superficiais das estações E1 e E2, enquanto que no período chuvoso as águas superficiais das três estações apresentaram concentrações de NID superiores às de MOP (Figura 5).

\section{Correlações e Integração espaço-temporal}

O período chuvoso apresentou correlação positiva de $\mathrm{pH}$ com salinidade e de $\mathrm{pH}$ com $\mathrm{OD}$, respectivamente 0,79 e 0,47 , indicando que o $\mathrm{pH}$ foi influenciado mais pela maré do que pelos processos biológicos atuantes no ambiente em estudo. Por outro lado, o período seco apresentou significativa correlação $(0,72)$ entre $\mathrm{pH}$ e OD, indicando que os processos biológicos também foram importantes, provavelmente favorecidos pelo maior tempo de residência da água. A influência da maré esteve ainda mais significativa neste período, já que a correlação entre $\mathrm{pH}$ e salinidade foi de 0,95 (Figura 6 ).

No período chuvoso, a significativa correlação negativa $(-0,96)$ entre nitrato e salinidade demonstrou que a pluviosidade foi uma importante via de entrada desta forma nitrogenada para as águas superficiais dos rios, uma vez que no período seco essa mesma correlação foi de $-0,18$ (Figura 6).

As salinidades superiores nas estações E1 e E2 responderam a maior influência marinha neste local do estuário, que provavelmente também refletiram nos valores mais elevados de $\mathrm{pH}$ devido as características alcalinas da água marinha, bem como aos maiores teores de OD, uma vez que a renovação da água pela oscilação da maré é mais efetiva nessas localidades 


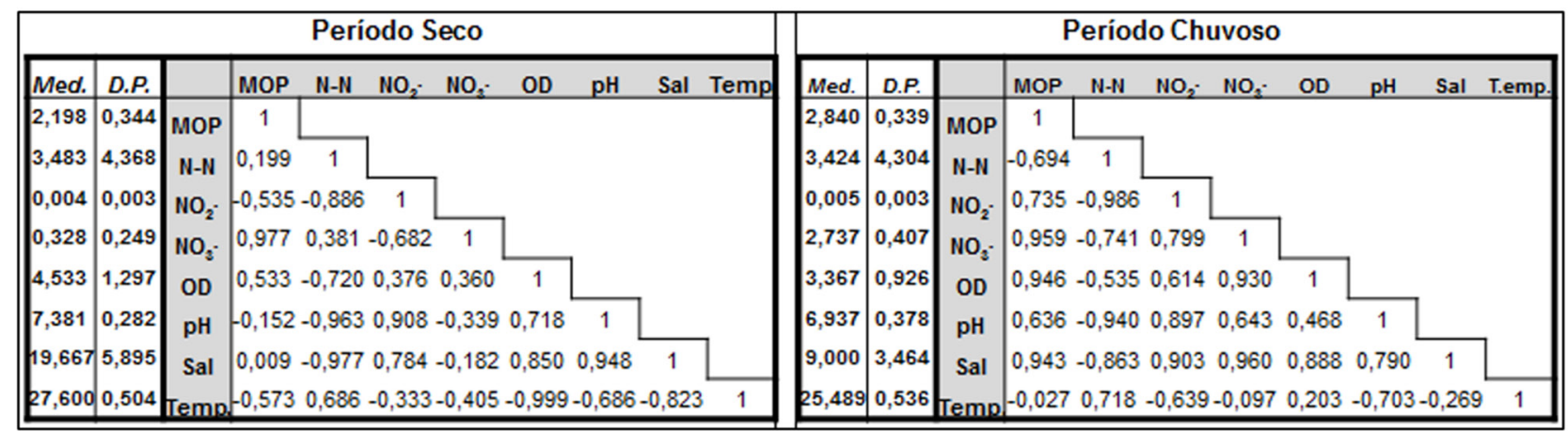

Figura 6 - Média, desvio padrão e P-valores das correlações de Pearson (significância em $p \leq 0,05$ ).

do que na região a montante do Crumaú (estação E3), onde a baixa circulação dificulta a dispersão dos nutrientes e proporciona intensa atividade decompositora, contribuindo também para os inferiores valores de $\mathrm{pH}$ e OD deste local.

No período chuvoso, a pouca variação de salinidade entre as estações E3 (montante) e E2 (jusante), bem como a intensificação das correntes de vazantes nas estações E1 e E2, demonstraram aumento no escoamento fluvial que, por sua vez, diminuiu a residência das águas no interior dos rios, inibindo a geração autóctone de NID. Por outro lado, o baixo escoamento fluvial e as maiores salinidades no período seco (Figura 2), sugerem maior eficiência no transporte vertical durante os ciclos das marés, o que intensifica a remineralização da matéria orgânica no interior dos rios e, consequentemente, a geração autóctone de NID.

\section{DISCUSSÃO}

As elevadas concentrações de N-N ( $\mathrm{N}$-amoniacal) e a baixa saturação do oxigênio dissolvido (\% Sat. OD) nas águas da estação E3 demonstraram elevada atividade decompositora neste trecho montante do Rio Crumaú. Segundo Piveli \& Kato (2006), elevadas concentrações de N-N em rios indicam proximidade de esgotos sanitários devido ao recente processo de decomposição do nitrogênio orgânico (o aterro sanitário do saco do funil e a comunidade residente em palafitas encontramse a aproximadamente $1 \mathrm{~km}$ a montante da estação E3). Em setembro de 2012 também foi observado concentrações de N-N acima de $9 \mathrm{mg} \cdot \mathrm{L}^{-1} \mathrm{em}$ águas superficiais desta mesma região do Rio Crumaú (Sutti et al., 2012).

Em lixiviados de aterros, Kalyuzhnyi \& Gladchenko (2004) encontraram faixas de concentrações de N-N e DQO (Demanda Química de Oxigênio) elevadas, respectivamente $780-1.080 \mathrm{mg} . \mathrm{L}^{-1}$ e $9.660-20.560 \mathrm{mg} . \mathrm{L}^{-1}$, relação que pode explicar os baixos teores de OD e MOP, bem como as elevadas concentrações de NID nas águas da estação E3. A decomposição é intensificada em aterros sanitários devido ao processo que drena o lixiviado mais antigo de camadas profundas para as camadas superiores, 0 que propicia a diminuição da concentração de matéria orgânica e o aumento da concentração do nitrogênio (Clabaugh, 2001). Isso indica que o chorume vazado de aterros sanitários proporcionam aos ambientes aquáticos maiores percentuais de $\mathrm{N}-\mathrm{N}$ e menores de matéria orgânica em relação os despejos de esgoto "in natura". De acordo com Lenzi et al. (2012), a massa seca comum dos esgotos "in natura" contém $45 \%$ de carbono e $1,5 \%$ de nitrogênio.

Segundo Leonard (2011), não importa quão bem arquitetados são os aterros, uma vez que a água da chuva encontrará os líquidos presentes no lixo e intensificará a formação do chorume, o qual, por sua vez, poderá ser infiltrado no solo e atingir águas superficiais e subterrâneas. O clima úmido da região e a proximidade do aterro sanitário ao leito do Rio Crumaú $(\approx 100 \mathrm{~m})$, são fatores que potencializam a incidência, via lixiviação, de nitrogênio nas águas a montante deste rio. Esta contribuição torna-se mais evidente ao se comparar valores de NID e MOP nas águas de outras áreas do sistema estuarino de Santos que não apresentam aterros sanitários.

No canal de São Vicente (região metropolitana da Baixada Santista), onde o despejo de esgoto "in natura" é a principal causa de eutrofização do meio, Moser et al. (2005) e Azevedo \& Braga (2011) encontraram valores máximos de $\mathrm{N}-\mathrm{N}$ relativamente similares, respectivamente 3,7 e 2,9 mg.L-1; que foram atribuídos à baixa hidrodinâmica do local. Deve ser destacado que a ocupação humana ao longo deste canal é relativamente mais antiga e densa que a existente no Rio Crumaú, no entanto, os valores são cerca de três vezes inferiores aos registrados na estação E3. Em outras áreas do sistema estuarino de Santos, valores similares aos encontrados a montante do Rio Crumaú foram registrados apenas no rio Mogi (complexo industrial de Cubatão), porém os efluentes 
locais não são apenas domésticos, mas também industriais (CETESB, 2010).

As principais fontes naturais de matéria orgânica para os corpos hídricos são oriundas dos produtores primários (autóctones) e da bacia de drenagem (alóctones) (Mash et al., 2004), sendo a fração particulada constituída em grande parte por detritos vegetais (Esteves, 1999). Os teores médios de matéria orgânica em suspensão observados por Azevedo \& Braga (2011) no canal de São Vicente ( $\approx 15$ $\left.\mathrm{mg} . \mathrm{L}^{-1}\right)$ foram mais expressivos que os encontrados no Rio Crumaú. A menor bacia de drenagem aliada à menor comunidade residente em palafitas nos arredores da nascente do Rio Crumaú podem explicar esta tendência, já que a intensa decomposição em aterros sanitários reduz a fração orgânica e aumenta o percentual de N-N.

Além do tamanho da bacia de drenagem, a magnitude das fontes naturais de nitrogênio e matéria orgânica para água estuarina também é influenciada pelo tamanho da área de manguezal integrada ao sistema (Dittmar, 2001; Pamplona et al., 2013). O regime pluviométrico de uma dada região costeira contribui para condicionar as áreas passíveis de ocupação da vegetação de manguezal (Lugo \& Snedaker, 1974), sendo também importante na regulação do intemperismo e saídas de elementos da bacia de drenagem (Lewis et al., 1987). Com base nisso, os valores de MOP e de NID das águas do preservado estuário de Cananéia (litoral sul de São Paulo) são importantes parâmetros de comparação para se avaliar o grau de eutrofização das águas do sistema estuarino de Santos, uma vez que as regiões apresentam mesma formação geológica e similaridade no ciclo hidrológico.

De acordo com Moser et al. (2005), o contínuo processo da decomposição de bosques de mangues estabelece um constante nível de N-N na água estuarina, condição que pode explicar a pouca variação entre os períodos nas águas das estações E1 e E2, onde há maior presença desses bosques devido a proximidade do canal de Bertioga. Através de uma estação localizada numa porção a nordeste deste canal, Gianesella et al. (2005) encontraram máxima concentração em torno de $0,7 \mathrm{mg} \cdot \mathrm{L}^{-1}$, similares às máximas nas jusantes dos rios Maratuã e Crumaú (estações E1 e E2) e ao limite imposto pelo CONAMA 357/05. Contudo, Braga et al. (2000) citam que estuários preservados, não associados com poluição por efluentes ou excesso de matéria orgânica, contribuem com cerca de 0,2 $\mathrm{mg} . \mathrm{L}^{-1}(1,5 \mu \mathrm{M})$ de $\mathrm{N}-\mathrm{N}$ às águas, similar aos valores encontrados no estuário de Cananéia por Azevedo \& Braga (2011).

Os sedimentos de estuários com presença de manguezais são fontes significativas de matéria orgânica e de nutrientes para coluna d'água (Rezende et al., 2007), no entanto a concentração nas águas superficiais é fortemente condicionada pela circulação regida pelas marés, como observado por Anand et al. (2014) no estuário de Zuari (Goa, Índia). A intensificação do escoamento fluvial no período chuvoso provavelmente tornou desprezível a contribuição de MOP e NID do sedimento às águas superficiais dos rios, sugerindo maior contribuição das fontes antrópicas. Por outro lado, o período seco apresentou salinidades mais elevadas nas águas superficiais e menor intensidade das correntes de vazante, o que sugere maior efetividade do transporte vertical. No entanto, esta suposta contribuição de MOP e NID às águas superficiais provavelmente também apresenta grande parcela antropogênica, uma vez que Ferreira (2002) observou um gradiente (montante-jusante) de contaminação por esgoto em sedimentos do Rio Crumaú.

O leve declínio de MOP observado no Rio Crumaú sentido montante-jusante (E3-E2) pode ser atribuído às áreas desmatadas ao longo de sua margem leste. De acordo com Troeh e Thompson (2007), desmatamentos e atividades agrícolas ocasionam redução da camada superficial do solo. Por outro lado, as maiores concentrações de MOP nas águas da estação E1 podem ser ocasionadas pela maior presença dos bosques de mangues, que teoricamente contribuem com maiores percentuais de carbono refratário, ao contrário do conteúdo antropogênico gerado a montante do Rio Crumaú. Segundo Clareto (1997), a fração orgânica de resíduos sólidos municipais é composta em sua maior parte ( 30\%) por substâncias solúveis e altamente biodegradáveis, já as substâncias refratárias representam apenas cerca de $5 \%$.

A nitrificação foi significativa nas águas da estação E1 (jusante do Rio Maratuã), uma vez que os percentuais de saturação de oxigênio dissolvido e de nitrato estiveram elevados em relação aos observados nas estações do Rio Crumaú, indicando um estágio mais avançado de decomposição devido a maior distância das fontes de esgoto. Por outro lado, os valores de OD obtidos no período chuvoso nas águas das estações E3 e E2 caracterizaram condições hipóxicas, como determinam Tribovillard et al. (2006) para ambientes com teores de OD inferiores a 2,87 mg. L-1. Segundo Savage (2005), a presença do esgoto sanitário em águas costeiras passa a acelerar o consumo de oxigênio e aumentar os teores de nitrogênio, o que estimula um rápido crescimento da população de microrganismos desnitrificantes.

As diferenças de teores de N-N entre os locais E3 e E2 sugerem a volatilização/desnitrificação como processos significativos na remoção do nitrogênio nas águas do Rio Crumaú. O maior tempo de residência da água e as mais elevadas temperaturas prova- 
velmente intensificaram esses processos no período seco. De acordo com Dettmann (2001), o processo de desnitrificação é intensificado em áreas estuarinas de baixo volume (prisma de maré), elevada residência da água e alta carga de nitrogênio. A intensificação deste processo está relacionada com o aumento da velocidade de reação que transforma o nitrogênio no sentido $\mathrm{NO}_{3} \rightarrow \mathrm{NO}_{2} \rightarrow \mathrm{N}-\mathrm{N} \rightarrow \mathrm{N}_{2}\left(\right.$ ou $\mathrm{N}_{2} \mathrm{O}$ ), contribuindo assim para as mais baixas concentrações de NID no período seco. No entanto, deve ser destacado que os valores de NID registrados no período chuvoso são atribuídos em sua maior parte pela adição de nitrato via pluviosidade.

A deposição atmosférica úmida é uma significativa entrada de nitrogênio para os ambientes aquáticos (Kroeger et al., 2006). Souza et al. (2006) observaram na composição da água da chuva em llha Grande (RJ), $\mathrm{pH}$ de 5,3 e valores de nitrato e amônio respectivamente de $3,3 \mathrm{mg} \cdot \mathrm{L}^{-1}$ e $0,8 \mathrm{mg} \cdot \mathrm{L}^{-1}$. Já na industrializada cidade de Cubatão ( $\approx 15 \mathrm{~km}$ da área de estudo), a água da chuva apresentou $\mathrm{pH}$ de 4,8 e valores de nitrato e amônio respectivamente de $4,8 \mathrm{mg} \cdot \mathrm{L}^{-1}$ e $1,85 \mathrm{mg} \cdot \mathrm{L}^{-1}$ (Silva Filho, 2011). Nestas condições de $\mathrm{pH}, \circ \mathrm{NH}_{4}^{+}$ torna-se estável, porém, ao atingir águas estuarinas de $\mathrm{pH}$ mais elevado $(\approx 6,5 \leq \mathrm{pH}<8,2)$, o mesmo tende a ser neutralizado a $\mathrm{NH}_{3}$. Além disso, a maioria dos íons amônio fica retida em locais de troca de cátions em diferentes tipos de solos (Troeh \& Thompson, 2007). Isto torna o nitrato a forma nitrogenada mais abundante em solução neste compartimento, o que permite intensa adição deste íon (via lixiviação e/ ou erosão) aos corpos aquáticos durante eventos de elevada pluviosidade. Esta contribuição pode ser expressiva em bacias de drenagem que apresentam áreas desmatadas e/ou atividades agrícolas, conforme Begon et al. (2007). O valor médio de nitrato observado no período chuvoso foi consideravelmente superior ao máximo $\left(\approx 0,1 \mathrm{mg} \cdot \mathrm{L}^{-1}\right)$ encontrado no preservado estuário de Cananéia por Azevedo \& Braga (2011).

As áreas de bananais ao longo da margem leste do Rio Crumaú podem representar uma contribuição de nitrato às águas da região de confluência desses rios. A bananeira é uma planta de crescimento rápido que necessita de concentrações elevadas de nutrientes, os quais podem ser fornecidos tanto pelo solo como pela ciclagem solo-planta (Borges \& Oliveira, 2000), sugerindo que essa monocultura proporciona maiores teores de nitrogênio ao solo do que as vegetações nativas, mesmo que não haja emprego de fertilizantes químicos. De acordo com Teixeira et al. (2008), os cachos das bananeiras cultivadas no Estado de São Paulo exportam percentuais consideravelmente elevados de nitrogênio em relação ao magnésio, fósforo, cálcio e outros, servindo como fertilizante orgânico, o qual, segundo estes autores, atende a demanda de pequenos produtores, como os encontrados nas encostas da serra de Santo Amaro ao longo da margem leste do Rio Crumaú.

Durante eventos de alta pluviosidade, Mallin et al. (1993) encontraram concentração de nitrato em torno de 1,3 mg. L-1 em tributários de um estuário da costa leste dos Estados Unidos, o que proporcionou eutrofização e elevada produção primária neste estuário. No período chuvoso, as elevadas concentrações de nitrato na estação E2 $\left(2,4 \mathrm{mg} \cdot \mathrm{L}^{-1}\right)$ demonstraram elevada exportação deste nutriente para o Largo do Candinho, indicando que esta área tende a apresentar eutrofizações após eventos de elevada pluviosidade. Esta área é relativamente de baixa circulação e profundidade (Harari \& Camargo, 1998), sendo assim uma das poucas do sistema estuarino de Santos em que se depositam sedimentos argilosos e com alta porcentagem de matéria orgânica (Zaroni, 2006).

Ao avaliar a dispersão do esgoto no Rio Crumaú por Escherichia coli, Sutti et al. (2015) observaram em período chuvoso elevada incidência desses microrganismos na jusante do Rio Maratuã durante a enchente da maré. Esta dinâmica pode explicar parte das elevadas concentrações de NID nas águas da estação E1, já que ao longo das margens deste rio o mangue é preservado e aparentemente não há fontes de esgoto. No entanto, a proximidade com o Rio Crumaú, pode fazer com que as águas subterrâneas sejam outra fonte de nitrogênio para o Rio Maratuã, principalmente em períodos chuvosos. Ao analisar a fertilização de uma cultura de bananas nas Ilhas Canárias (Espanha), Muñoz-Carpena et al. (2002) observaram que 53\% do nitrogênio é transferido (principalmente na forma de nitrato) às águas subterrâneas durante intensa irrigação e/ou pluviosidade.

As concentrações de nitrato nas jusantes dos rios Maratuã e Crumaú são similares às encontradas por Azevedo \& Braga (2011) no canal de São Vicente, porém consideravelmente inferiores às encontradas por Chiozzini et al. (2011) e Masuda et al. (2010) no canal de Santos, onde ambos os estudos apresentaram valores máximos em torno de $10 \mathrm{mg} . \mathrm{L}^{-1}$. Além das palafitas, esses valores podem ser explicados pelas fábricas de fertilizantes no pólo industrial de Cubatão e pela movimentação desta carga no canal de Santos.

Como mencionado por Baird (2002), o nitrito geralmente se apresenta em concentrações consideravelmente inferiores às de nitrato no ambiente, devido à sua instabilidade na presença do oxigênio. No entanto, em ambientes estuarinos ainda não é claro o papel da microbiota na manutenção deste quadro, ainda mais naqueles que recebem cargas elevadas de nitrogênio. Mesmo caracterizando a desnitrificação como o processo mais significativo na remoção do 
nitrogênio em estuários tropicais (onde ocorrem manguezais), Fernandes et al. (2012) também citaram o processo Anammox (Anaerobic ammonium oxidation) como influentes na transformação do nitrogênio em sedimentos deste ecossistema.

O processo Anammox foi descoberto em experimentos em reatores de tratamento de esgotos, onde foi observada a oxidação do amônio em condições anóxicas, na qual o nitrito (e não o nitrato) é o aceptor de elétrons deste processo (Schmidt et al., 2003). No entanto, Tang et al. (2010) citam que o elevado conteúdo biodegradável de esgotos estimula um rápido crescimento de desnitrificantes, consumindo mais rapidamente o nitrito que as bactérias Anammox. Este fator pode estar contribuindo para a não detecção de nitrito nas amostras da estação E3 e para as baixas concentrações de nitrato no período seco.

No sistema estuarino de Santos, Berbel et al. (2015) concluíram que os altos percentuais de fósforo orgânico e N-amoniacal nos canais do porto e São Vicente não podem ser atribuídos somente a matéria orgânica autóctone e alóctone, mas também aos resíduos domésticos. A concentração $\left(\approx 1 \mathrm{mg} \cdot \mathrm{L}^{-1}\right)$ média de NID obtida nas águas do preservado estuário de Cananéia por Azevado \& Braga (2011) sugerem que as fontes antrópicas de nitrogênio para as águas dos rios Maratuã e Crumaú sejam mais expressivas que às naturais. A concentração média de NID obtida neste estudo foi de aproximadamente $5 \mathrm{mg} \cdot \mathrm{L}^{-1}$.

\section{CONCLUSÃO}

Os resultados das determinações das principais formas de Nitrogênio Inorgânico Dissolvido (NID) associados aos de Matéria Orgânica Particulada (MOP), revelaram dinâmicas distintas entre os períodos e entre os locais estudados, gerando informações que somam para o conhecimento do ciclo biogeoquímico do nitrogênio em estuários subtropicais do Brasil. As intervenções antropogênicas na região estuarina centronorte da llha de Santo Amaro puderam ser observadas com base nas formas de nitrogênio determinadas, que assim demonstraram ser importantes no diagnóstico da poluição orgânica nas águas deste ecossistema.

Os baixos teores de OD e as elevadas concentrações de $\mathrm{N}$-amoniacal nas águas a montante do Rio Crumaú coloca esta área como uma das mais deterioradas do sistema estuarino de Santos. Os elevados teores de NID sugerem as fontes antrópicas como mais expressivas que às naturais, que também inclui a remineralização da matéria orgânica produzida pelos manguezais. Deste modo, a caracterização do intenso escoamento fluvial nos rios Maratuã e Crumaú no período chuvoso traz um alerta de eutrofizações também em águas do Canal de Bertioga, caso medidas de melhoria de âmbito socioambiental não sejam tomadas pelas autoridades competentes.

\section{REFERÊNCIAS BIBLIOGRÁFICAS}

Anand, S.K.J.; Mathew, D.M.; Kumar, D. 2014. Subhourly changes in biogeochemical properties in surface waters of Zuariestuary, Goa. Environ. Monit, 186(2), 719-724.

American Public Health Association (APHA). 1999. Standard methods for examination of water and wastewater. $20^{\circ}$ Edição, Washington. Port City Press.

American Public Health Association (APHA). 2005. Standard methods for the examination of water and wastewater. $2^{\circ}$ Edição. Washington. Port City Press.

Associação Brasileira de Normas Técnicas (ABNT). 1989. NBR10664: Águas-Determinação de resíduos (sólidos) - Método gravimétrico. Rio de Janeiro.

Azevedo J.S. \& Braga E.S. 2011. Caracterização hidroquímica para qualificação ambiental dos estuários de Santos-São Vicente e Cananéia. Arq. Ciên. Mar. 44(2): 52-61.

Baird, C. 2002. Química Ambiental. Tradução: Receio, M.A.L. \& Carrera, L.C.M. $2^{\circ}$ Edição, Porto Alegre, Bookman, 622p.

Begon, M.; Townsend, C.R.; Harper, J.L. 2007. Ecologia: De Indivíduos a Ecossistemas. $4^{\circ}$ Edição, Porto Alegre, Artmed, 740p.

Berbel, G.B.B.; Favaro, D.I.T.; Braga, E.S. 2015. Impact of harbour, industry and sewage on the phosphorus geochemistry of a subtropical estuary in Brazil. Marine Pollution Bulletin, (1-2):44-52.

Borges, A.L.; Oliveira, A.M.G. 2000. Nutrição, adubação e calagem. In: Cordeiro, Z.J.M. (ed.). Banana: produção: aspectos técnicos. Brasília. Embrapa. 47-59pp.

Braga, E.S. 2002. Bioquímica marinha e efeitos da poluição nos processos bioquímicos. $2^{\circ}$ Edição, Instituto Oceanográfico da USP, FUNDESPA, $90 \mathrm{p}$.

Braga, E.S.; Bonetti, C.V.D.H.; Burone B,L.; Bonetti Filho, J. 2000. Eutrophication and bacterial pollution caused by industrial and domestic wastes at the Baixada Santista estuarine system (Brazil). Marine Pollution Bulletin, 40(2), 165-173.

Centro de Previsão de Tempo e Estudos Climáticos (CPTEC). 2013. Disponível em: http://www.cptec. inpe.br. Acessado em 12 out. 2012.

Centro Integrado de Informações Agrometeorológicas (CIIAGRO). 2013. Disponível em http://www. ciiagro.sp.gov.br. Acessado em 02/07/2013. 
Chiozzini, V.G.; Maluf, J.C.C.; Torres, J.L.R.; Braga, E.S. 2011. Balanço entre as formas nitrogenadas dissolvidas como indicador de qualidade das águas no sistema estuarino de Santos - São Vicente, São Paulo (Brasil). V Simpósio Brasileiro de Oceanografia (V SBO). Anais. Santos-SP.

Clabaugh, M.M. 2001. Nitrification of landfill leachate by biofilm columns. Dissertação de Mestrado, Virginia Polythecnic Institute and State University, USA, 43p.

Clareto, C.R. 1997. Tratamento biológico de líquidos percolados gerados em aterros sanitários utilizando reator anaeróbio compartimentado, São Carlos. Dissertação de Mestrado. Universidade de São Paulo, Escola de Engenharia de São Carlos EESC, 88p.

Companhia de Tecnologia de Saneamento Ambiental (CETESB). 2010. Relatório da qualidade das águas interiores do Estado de São Paulo. Relatório Técnico Cetesb, v.1, 310p.

Conselho Nacional do Meio Ambiente (Conama). 2005. Resolução $n^{\circ}$ 357, de 17 de março de 2005. 928p.

Dettmann, E.H. 2001. Effect of water residence time on annual export and denitrification of nitrogen in estuaries: a model analysis. . Estuaries, 24(4), 481-490.

Dittmar, T. \& Lara, R.J. 2001. Driving forces behind nutrient and organic matter dynamics in a mangrove tidal creek in north Brazil. Estuarine, Coastal and Shelf Science, 52(2), 249-259.

Esteves, F.A. 1998. Fundamentos da Limnologia. Rio de Janeiro. Interciência. 457p.

Fernandes, S.O.; Michotey, V.D.; Guasco, S.; Bonin, P.C.; Bharathi, P.A.L. 2012. Denitrification prevails over anammox in tropical mangrove sediments (Goa, India). Marine Environmental Research, $74,9-19$,

Ferreira, T.O. 2012. Solos de mangue do rio Crumahú (Guarujá-SP): pedologia e contaminação por esgoto doméstico. Dissertação de Mestrado. Universidade de São Paulo. Escola superior de agricultura Luiz de Queiroz, Piracicaba-SP. 113p.

Galloway, J.N.; Townsend, A.R.; Erisman, J.W.; Bekunda, M.; Cai, Z.; Freney, J.R.; Martinelli, L.A.; Seitzinger, S.P.; Sutton, M.A. 2008. Transformation of the nitrogen cycle: ontent trends, questions, and potential solutions. Science, 320, 889-892.

Gianesella, S.M.F.; Saldanha-Corrêa, F.M.P.; Miranda, L.B.; Corrêa, M. A.; Moser G.A.O. 2005. Shortterm variability and ontente ími ontente í and chlorophyll-a in Bertioga Channel, São Paulo State, Brazil. Brazilian Journal of Oceanography, 53(3-4), 94-114.

Harari, J. \& Camargo, R. 1998. Modelagem numérica da região costeira de Santos (SP): Circulação de maré. Brazilian Journal of Oceanography, 46(2), 135-156.

Kalyuzhnyi, S. \& Gladchenko, M. 2004. Sequenced anaerobic-aerobic treatmant of high strength, Strong nitrogenous landfill leachates. Water Science and Technology, 49(5-6), 301-312.

Kroeger, K.D; Cole, M.L.; Valiela, I. 2006. Groundwatertransported dissolved organic nitrogen exports from coastal watersheds. Limnology and Oceanography, 51(5), 2248-2261.

Lewis, W.M.; Hamilton, S.K.; Jones, S.L.; Runnels, D.D. 1987. Major element chemistry, weathering and element yields for the Caura River drainage, Venezuela. Biogeochemistry, 4,159-181.

Lenzi, E.; Favero, L.O.B.; Luchese, E.D. 2012. Introdução à química da água: ciência, vida e sobrevivência. Rio de janeiro, LTC, 604p.

Leonard, A. 2011. A história das coisas, o que acontece com tudo que consumimos. Revisão técnica: Besserman, A.P, Zahar, 302p.

Lugo, A.E.; Snedaker, S.C. 1974. The Ecology of Mangroves. Annual Review of Ecology and Systematics, 5, 39-64.

Mallin, M.A.; Paerl, H.W.; Rudek, J.; Bates, P.W. 1993. Regulation of estuarine primary production by watershed rainfall and river flow. Marine ecology progress series, 93, 199-203.

Mash, H., Westerhoff P. K., Baker L. A., Nieman R. A., Nguyen M. L. 2004. Dissolved organic matter in Arizona reservoirs: assessment of carbonaceous sources. Organic Geochemistry. 1-13p.

Miranda, L. B. de; Castro, B. M. de; Kjerfve, B. 1998. Circulation and mixing due to tidal forcing in the Bertioga Channel, São Paulo, Brazil. Estuaries, v.21(2), 204-214.

Miranda, L. B. de; Castro, B. M. de; Kjerfve, B. 2002. Princípios de Oceanografia Física de Estuários. Editora da Universidade de São Paulo, 427p.

Moser, G.A.O.; Gianesella, S.M.F.; Barrera Alba, J.J.; Bérgamo, A.L.; Saldanha Corrêa, F.M.P.; Miranda, L.B.; Hariri, J. 2005. Instantaneous transport of salt, nutrients, suspend matter and chlorophyll-a in the tropical estuarine system of Santos. Brazilian Journal of oceanography, 53(3-4), 115-127.

Muñoz-Carpena, R.M.; Ritter, A.; Socorro, A.R.; Pérez, N. 2002. Nitrogen evolution and fate in a Canary Islands (Spain) sprinkler fertigated banana plot. Agricultural Water Management, 52(2),93-117.

Nunes, L.H. 1997. Distribuição espaço-temporal da pluviosidade no Estado de São Paulo: variabilidade, tendências, processos intervenientes. Tese de doutorado. Escola Politécnica da Universidade de São Paulo, 192 p.

Ovalle, A.R.C.; Rezende, C.E.; Lacerda, L.D.; Silva, C.A.R. 1990. Factors affecting the hydrochemistry 
of a Mangrove Tidal Creek, Sepetiba Bay, Brazil. Estuarine, Coastal and Shelf Science, 31(5), 639-650.

Pamplona, F.C.; Paes, E.D.; Nepomuceno, A. 2013. Nutrient fluctuations in the Quatipuru river: $A$ macrotidal estuarine mangrove system in the Brazilian Amazonian basin. Estuarine, Coastal and Shelf Science, 133, 273-284.

Pereira, R.S. 2004 Identificação e caracterização das fontes de poluição em sistemas hídricos. Revista Eletrônica de Recursos Hídricos. IPH - UFRGS, 1, 20-36.

Piveli, R.P. \& Kato, M.T. 2006. Qualidade da água e poluição: aspectos físico-químicos. São Paulo, ABES, 285p.

Prista, G. 2012. Águas marinhas e estuarinas: métodos de amostragem e armazenamento para nutrientes. Ecologi@, 4, 69-75.

Rabelais, N.N.; Turner, R.E.; Dortch, Q.; Justic, D.; Bierman Jr., V.J.; Wiseman Jr., W.J. 2002. Nutrientenhanced productivity in the northern Gulf of Mexico: past, present and future. Hydrobiologia, 475(5), 39-63.

Rezende, C.E.; Lacerda, L.D.; Ovalle, A.R.C.; Silva, L.F.F. 2007. Dial organic ontent fluctuations in a mangrove tidal creek in Sepetiba bay, Southeast Brazil. Brazilian Journal of Biology, 67(4), 673-680.

Savage, C. 2005. Tracing the influence of sewage nitrogen in a coastal ecosystem using stable nitrogen isotopes. Ambio, 34(2), 145-150.

Schmidt, L.; Slekers, O.; Schmid, M.; Bock, E.; Fuerst; Kuenen, J.G.; Jetten, M.S.M.; Strous, M. 2003. New concepts of microbial treatment processes for the nitrogen removal in wastewater. FEMS Microbiology Reviews. 27(4), 481-492.

Schmiegelow, J.M.M. \& Geanesella, S.M.F. 2014. Absence of zonation in a mangrove forest in southeastern Brazil. Brazilian Journal of Oceanography, 62(2), 117-131.

Silva Filho, M.V. 2011. Avaliação dos efeitos locais na composição química de águas de chuva nas cidades de São Paulo e Cubatão. Dissertação de Mestrado. Universidade de São Paulo, Instituto de Astronomia, Geofísica e Ciências Atmosféricas.
Souza, P.A.; Mello, W.Z.; Madonado, J. 2006. Composição química da chuva e aporte atmosférico na llha Grande, RJ. Química. Nova, 29(3), 471-476.

Sutti, B.O.; Chiaratti, B.M.; Schmiegelow, J.M.M.; Guimarâes, L.L.; Borges, R.P. 2012. Caracterização da qualidade das águas superficiais do rio Crumaú, principal área de drenagem da ilha de Santo Amaro para o canal de Bertioga, litoral central de São Paulo. Unisanta BioScience, 1(2), 65-70.

Sutti, B.O.; Schmiegelow, J.M.M.; Guimarâes, L.L.; Borges, R.P. 2015. Avaliação de Escherichia coli como sinalizadora de esgoto sanitário em sistemas estuarinos: estudo de caso em dois rios tributários do canal de Bertioga. Unisanta BioScience, 4(1), 16-24.

Tang, C.; Zheng, P.; Wang, C.; Mahmood, Q. 2010. Suppression of anaerobic ammonium oxidizers under high organic ontente in high-rate Anammox UASB reactor. Bioresource Technology, 101(6), 1762-1768.

Teixeira L.A.J.; Raij, B.V.; Neto, J.E.B. 2008. Estimativa das necessidades nutricionais de bananeiras do subgrupo Cavendish cultivadas no Estado de São Paulo. Revista Brasileira de Fruticultura, 30(2), 540-545.

Tribovillarda, N.; Algeob, T.J.: Lyonsc, T; Riboulleaua, A. 2006. Trace metals as paleoredox and paleoproductivity proxies. An update Chemical Geology, 232, 12-32.

Troeh, F.R. \& Thompson, L.M. 2007. Solos e fertilidade do solo. $6^{\circ}$ Edição. Tradução: Neto, D.D. \& Manuella, D.N. São Paulo: Organização Andrei Editora Ltda, 718p.

Zaroni, L.P. 2006. Avaliação da qualidade dos sedimentos marinhos e estuarinos no município de Bertioga-SP. Tese de Doutorado. Universidade de São Paulo, Instituto Oceanográfico. 211p.

Submetido: Janeiro/2015 Revisado: Abril/2015 Aceito: Fevereiro/2016 